\title{
TEXTOS LITERÁRIOS E A FORMAÇÃO DO PROFESSOR: NOVAS POSSIBILIDADES DE NARRAR
}

\author{
Eda Maria de Oliveira Henriques*
}

\begin{abstract}
RESUMO: O presente trabalho aborda a importância do uso do texto literário como veículo de expressão e (re)leitura de sentidos sobre várias dimensões do processo de ensinar e aprender, constituídas ao longo das trajetórias de formação do professor. Para isso, se apoia na concepção de crítica de leitor desenvolvida pelo jovem Vigotski, em seu trabalho $A$ tragédia de Hamlet, príncipe da Dinamarca, e na idéia defendida por Iser, um dos autores da teoria literária denominada estética da recepção, do texto como campo de jogo onde autor, texto e leitor se interconectam, produzindo algo que antes não existia. Tais concepçóes fundamentaram a construção de uma metodologia de pesquisa, realizada junto a alunos de licenciatura da Universidade Federal Fluminense, que, ao propor um trabalho de crítica de leitor com obras literárias que remetem ao universo escolar, viabilizou um espaço de narrativas e uma rede de histórias entre o texto e suas experiências de formação, bem como um campo de reflexão e análise para o futuro exercício da docência.
\end{abstract}

Palavras-chave: Literatura. Formação. Professor. Narrativa.

\section{LITERARY TEXTS AND TEACHER TRAINING: NEW NARRATIVE POSSIBILITIES}

ABSTRACT: This paper addresses the importance of using literary texts as a vehicle for expression and for (re) reading the different meaning dimensions in the process of teaching and learning formed along the paths of teacher training. It will be based on the critical reader concept developed by the young Vygotsky in his

Doutora em Educação e professora do Departamento de Fundamentos Pedagógicos da Universidade Federal Fluminense (UFF). E-mail: edahenriques@gmail.com 
work "The Tragedy of Hamlet, Prince of Denmark" and the idea defended by Iser, one of de authors of the esthetic of reception literary theory, where the text works as a playing field where the author, text and reader, are interconnected by producing something that did not exist before. These concepts motivated the construction of one research methodology, ran with the undergraduate students from the Fluminense Federal University, proposing a critical reader task with literary texts connected to the school world, which enabled a space of narratives and stories between the text and their training experiences as well as to consider and analyze the future exercise of teaching

Key words: Literature. Teacher Training. Narrative. School.

\section{Introdução}

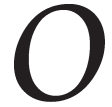

presente trabalho, desenvolvido a partir da pesquisa "Processos de formação: construindo novos sentidos para o conhecimento e a aprendizagem", pretende abordar a importância do uso do texto literário como veículo de expressão e (re)leitura de sentidos sobre várias dimensões do processo de conhecimento, instituídas ao longo das trajetórias de formação inicial do professor, especialmente as dimensóes voltadas para as relações do ensinar e do aprender. Isto porque, ao refletir sobre a complexidade do processo de conhecimento e de significação na formação de professores, em especial sobre as licenciaturas, esta pesquisa procura contribuir para uma discussão de um processo mais integrado entre cursos básicos (disciplinas de conteúdo específico) e formação pedagógica (disciplinas de conteúdo pedagógico), que tradicionalmente tem se organizado de forma fragmentada e dicotômica, privilegiando um modelo de racionalidade técnica em que disciplinas de conteúdo específico precedem disciplinas de conteúdo pedagógico, articulando-se pouco com elas.

Assim, entendendo que os cursos básicos também possuem um potencial formador no que diz respeito à dimensão pedagógica, tornase importante que as disciplinas da licenciatura integrem, em suas discussões e propostas, concepções e modelos pedagógicos já construídos pelos alunos ao longo de sua trajetória de formação, mas, sobretudo, a partir das experiências pedagógicas vividas nas disciplinas de conteúdo específico. 
Embora as disciplinas da licenciatura procurem abordar de forma reflexiva questões conceituais e práticas relacionadas às situações de ensino/aprendizagem formal, precisam interagir com concepçôes e modelos de ensino constituídos por meio da mediação das mais diversas práticas formadoras da experiência escolar e acadêmica, que, muitas vezes, centralizam o processo na figura do professor e perpetuam, como diria Castoriadis (1991), a partir de registros de ordem simbólica e imaginária, as mais tradicionais crenças sobre a escola e os processos em torno do ensinar e aprender.

Nesta perspectiva, para viabilizar esta identificação e análise das concepções dos alunos da licenciatura, constituídas ao longo de suas trajetórias de formação, pensou-se em uma metodologia que, ao recorrer ao potencial simbólico do texto literário, procura viabilizar e mediar narrativas que pudessem contornar a questão das respostas prontas e estereotipadas tão comuns nas entrevistas tradicionais, promovendo um diálogo entre a leitura da experiência de formação e a literatura como uma experiência na formação do professor.

Para isso, o presente artigo se apoiará na concepção de crítica de leitor desenvolvida pelo jovem Vigotski, em seu trabalho $A$ tragédia de Hamlet, principe da Dinamarca, no qual faz uma abordagem desta obra de Shakespeare a partir de uma crítica subjetiva, de impressão artística imediata, em que defende a ideia de que a obra de arte, após sua criação, separa-se de seu autor e é recriada pelo leitor, a partir da multiplicidade polissêmica de toda obra, permitindo ao crítico fazer revelações que o autor nem sequer suspeitava.

Nessa perspectiva, a força da obra não se encontra no que o autor subtendeu por ela; a interpretação do autor é apenas mais uma dentro da multiplicidade de possíveis interpretações. Apesar de Vigotski reescrever nove anos depois o ensaio sobre Hamlet, publicado em Psicologia da Arte, com uma orientação mais objetiva, suprimindo o que Bezerra (1999) chama de interpretação simbolista da tragédia, essa primeira abordagem crítica se anuncia precursora em duas importantes direçôes. Em uma delas, Vigotski, ao desenvolver a ideia da intradutibilidade da impressão artística, remete ao fato de que um dos aspectos da mesma pode ser atribuído às angústias da palavra e ao abismo que separa o pensamento da expressão, adiantando sua futura discussão sobre a complexidade da relação pensamento-palavra desenvolvida numa perspectiva conceitual, no capítulo sete do livro Pensamento e linguagem. 
Textos literários e a formação do professor: novas possibilidades de narrar

$\mathrm{O}$ outro aspecto precursor, deste primeiro ensaio crítico sobre Hamlet, refere-se ao fato de que, de acordo com Bezerra (op. cit.), na sua concepção de crítica de leitor, Vigotski, ao afirmar que nenhuma obra literária existe sem o leitor, antecipa em algumas décadas a crítica da recepção. Ideia da qual parece compartilhar Wolfang Iser, um dos representantes da estética da recepção, desenvolvida a partir de 1967, em especial na Alemanha, ao colocar o texto como campo de jogo onde autor, texto e leitor se interconectam, produzindo algo que antes não existia.

A partir destas reflexões, constituiu-se uma proposta metodológica inspirada na perspectiva da crítica de leitor, desenvolvida por Vigotski, e na ideia do texto como campo de jogo, desenvolvida por Iser, onde um grupo de alunos de licenciatura da Universidade Federal Fluminense - dos cursos de Geografia, História, Letras, Química, Ciências Sociais, Matemática e Serviço Social - foi convidado a realizar suas leituras e a relatar livremente suas impressões a respeito de contos e crônicas da literatura brasileira que remetiam a situaçóes e questóes de escola.

O registro de tais leituras viabilizou uma rede de narrativas entre o texto e as diversas vivências de formação em torno do ensinar e aprender dos licenciandos, bem como se constituiu em campo de reflexão e análise sobre a importância do relato de tais experiências e concepçôes para o próprio curso de formação de professores e o futuro exercício da docência.

A seguir, apresenta-se um olhar mais aprofundado sobre as contribuições da noção de crítica de leitor em Vigotski e da concepção de jogo do texto em Iser, na tessitura de uma proposta metodológica que investe no potencial simbólico dos textos literários como mediadores de narrativas que, através de histórias de escola contadas em contos e crônicas da literatura brasileira, contam outras histórias sobre trajetórias de formação.

\section{A crítica de leitor: o leitor sujeito de seu processo de interpretação}

É dentro desse espírito, ou seja, numa defesa implícita de um projeto de leitor sujeito de seu processo de interpretação, que o jovem Vigotski (1999), em um trabalho de conclusão de curso escrito em 
1915, tratou da relação do crítico com o autor e sua obra, em $A$ tragédia de Hamlet, príncipe da Dinamarca. Nesta perspectiva, a obra é apenas uma possibilidade que o autor realiza, podendo o mesmo inclusive desconhecer a sua profundidade, e levar o crítico a revelações que ele como autor nem sequer suspeitava, o que faz com que a força da obra não esteja naquilo que o autor subentendeu por ela, mas na maneira como esta age sobre o leitor.

Desse modo, a leitura não está presa a um modelo semântico fechado, mas se abre sempre e infinitamente para a diversidade e universos onde o leitor a enfoca; universos que podem conter experiências de vida, experiências de leitura, experiências em torno do ensinar e do aprender. Assim, é o texto que se oferece com seu potencial simbólico na construção de outras narrativas, para a superação da angústia da palavra, do inexprimível de alguns sentidos, do indizível do discurso interior.

Neste trabalho, Vigotski, como foi dito anteriormente, antecipa sua futura discussão sobre a relação pensamento-linguagem, onde se destaca a questão da complexidade da passagem do pensamento à palavra, que, nesta perspectiva, não se trata de uma tradução direta da linguagem interior para a linguagem exterior, nem de uma simples incorporação do aspecto sonoro ao aspecto silencioso da fala, mas da "(...) reestruturação da linguagem, a transformação de uma sintaxe absolutamente original, da estrutura semântica e sonora da linguagem interior em outras formas estruturais inerentes à linguagem exterior" (Vigotski, 2001, p. 474).

Dessa forma, a passagem da linguagem interior para a exterior consiste em uma transformação dinâmica, ou seja, na transformação de uma linguagem predicativa e idiomática em uma linguagem sintaticamente decomposta e acessível a todos. Assim, o pensamento é sempre algo integral, compacto, maior em sua extensão e volume do que uma palavra isolada. $\mathrm{O}$ que no pensamento existe em simultaneidade, na linguagem se desenvolve sucessivamente.

Para Vigotski (2001), a complexidade da decomposição do pensamento e sua recriação em palavras se devem ao fato de que o pensamento não coincide com as palavras e com os seus significados, o que faz com que a transição do pensamento à palavra passe pelo significado e que, em nosso pensamento, sempre exista um subtexto oculto. Nesse sentido, há uma imperfeição da palavra na possibilidade de expressar o 
Textos literários e a formação do professor: novas possibilidades de narrar

pensamento, pois este nunca é igual ao significado direto das palavras. Isso leva o autor a afirmar que o caminho entre o pensamento e a palavra é um caminho indireto, internamente mediatizado pelo significado.

Tal constatação tem como consequência o fato de que a comunicação imediata entre as consciências seja impossível psicologicamente, só podendo ser atingida de forma indireta, pelo significado das palavras. Ao que o autor acrescenta que, para entendermos o discurso do outro, não é necessário entender apenas algumas palavras, mas é preciso compreender, também, seu pensamento e, principalmente, o motivo que o levou a emiti-lo.

A compreensão efetiva e plena do pensamento de outrem só se torna possível quando descobrimos o que Vigotski (op. cit., p. 187) denomina de "base afetivo-volitiva", que encerra o desejo que está na origem de todo o pensamento.

Dessa forma, a crítica de leitor oferece a possibilidade de superar o indizível, o inexprimível do discurso interior que Vigotski (1999), metaforicamente, remete a tirar sons de um instrumento rebelde, enquanto ouve com o ouvido da alma uma melodia potente e triste.

$\mathrm{O}$ criar com a própria alma a obra alheia significa compromisso apenas com a sua interpretação, sem a preocupação a respeito de outros estudos sobre a obra. A possibilidade de transformar a experiência da leitura no que Vigotski denominou de crítica estética, promovendo o crítico a crítico artista (crítico criador), traz não só novas possibilidades de significação através do potencial simbólico do texto, como também outras possibilidades de ressignificação dos sentidos em torno das experiências do ensinar e do aprender. Tais vivências, geralmente, são marcadas por práticas educativas escolarizadas, que, por suas próprias características, muitas vezes não viabilizam uma maior comunicação entre pensamentos de professores e alunos e dos próprios alunos entre si, através da compreensão dos desejos e necessidades, interesses e emoções, que estão na base do significado das palavras.

Essa abordagem viabiliza ao professor conhecer não só o conteúdo objetivo da experiência do aluno, mas também o sentido da mesma e os atos de pensamento que os apreendem. Nesta perspectiva, entendendo que o texto literário pode vir a tornar-se veículo de revelação e ressignificação de experiências e concepçôes que nem sempre encontram espaço 
de expressão na sala de aula - e na medida em que, na perspectiva da crítica de leitor, deixar falar a obra pelo leitor é também deixar o leitor se falar pela obra -, podemos aceitar o convite de Iser de entrar no jogo do texto, e de nos permitir ser jogados por ele num processo de composição de vários cenários e múltiplas realidades.

\section{O jogo do texto: o leitor como produtor de múltiplas realidades}

Para Iser (2002), a ideia de que autor, texto e leitor estão intimamente conectados em uma relação que produz algo que antes não existia se contrapõe à noção tradicional de representação, relacionada a uma realidade pré-dada que se pressupõe estar representada. Assim, a ideia de jogo do texto pretende privilegiar o aspecto performativo da relação autor-texto-leitor, onde o pré-dado não é concebido como objeto de representação, mas como a relação através da qual algo novo é modelado.

Nessa perspectiva, autores jogam com os leitores e o texto é o campo do jogo (Iser, 2002, p. 107) e, nesse jogo, o texto é composto por um mundo que desafia o leitor a imaginá-lo e a interpretá-lo, levando o mesmo a visualizar as múltiplas formas possíveis de imaginar o mundo do texto, que, nesse sentido, começa a sofrer modificações.

De acordo com o autor, não importam as novas formas que o leitor produz, todas transgridem e modificam o mundo contido no texto. $\mathrm{O}$ aspecto ficcional do texto invoca, então, um contrato entre autor e leitor, onde o mundo textual deve ser concebido não como realidade, mas como se fosse realidade (idem, ibid., p. 107). Isto é, embora possa repetir uma realidade identificável, o que acontece dentro dele não acarreta as consequências relativas ao mundo real referido. Essa dimensão assinala a esfera ficcional em que tudo deve ser considerado como se fosse o que parece ser, ou seja, como um jogo.

Dessa forma, o jogo que se encena no texto não é um espetáculo que o leitor apenas observa, mas um evento em processo que demanda sua participação nos procedimentos e na encenação e, ao realizar o jogo do texto a seu modo, o leitor produz um "suplemento" individual, que considera como o significado do texto.

O significado do texto torna-se uma espécie de "suplemento" que é gerado por meio do jogo, como algo que se adiciona ao texto, não 
Textos literários e a formação do professor: novas possibilidades de narrar

havendo, portanto, significado prévio ao jogo. De acordo com o autor, a produção do "suplemento" por meio do jogo compreende diferentes desempenhos por diferentes leitores no ato da recepção, que incluem desde o alcance da "vitória" com o estabelecimento do significado, ou com a manutenção do jogo livre, com a conservação em aberto do significado.

A unicidade do jogo estaria, então, no fato de que ele produz (suplementos) e, ao mesmo tempo, permite que o processo de produção seja observado; o que leva o leitor a uma duplicidade inexorável, isto é, participa de uma ilusão sabendo que é uma ilusão. Será, então, nessa oscilação entre ilusão fechada e ilusão revelada que a transformação efetivada pelo jogo do texto se fará sentir pelo leitor.

De acordo com Iser (2002), a transformação promovida pelo jogo do texto pode encaminhar a várias formas de conclusão do jogo, que representam tendências através da quais o mesmo pode ser realizado. Uma delas é em termos de semântica. Neste caso, o que predomina é a necessidade de compreensão e a premência da apropriação das experiências vividas, como uma forma de aplacar a ansiedade provocada pelo não familiar. Outro modo de jogar o texto poderia consistir na obtenção de experiência, em que há uma abertura para o não familiar e para a influência de outros valores e concepçóes. Um terceiro modo de jogo seria o do prazer, onde o que move a realização do jogo é a circunstância de possibilitar um contato com as próprias faculdades de pensar, imaginar, sentir o que tornaria cada um mais presente a si mesmo.

Ao refletir sobre o que é o jogo e porque jogamos, Iser (op. cit.) remete ao jogo de "faz de conta" da criança, quando esta consegue separar percepção e significado. Ao montar um cavalo de pau, ela realiza um jogo que consiste em desmembrar o objeto (cavalo) e o significado do objeto no mundo real e, dessa forma, por meio do que o autor chama de uma encenação, permite que limitações reais sejam ultrapassadas.

Da mesma forma, no jogo do texto há uma encenação que permite a transposição de fronteiras na qual a transformação encenada permite não só tornar acessível o inacessível, mas tornar o inacessível tanto presente como ausente. Torna presente pela transformação encenada e ausente pela constatação que a transformação encenada é "tão só-jogo" (idem, ibid., p. 118). Por permitir ter a ausência como presença, o jogo do texto viabiliza através da literatura uma forma de extensão a si 
mesmo, pois a forma como se imagina e se realiza uma encenação diz muito de seu realizador.

Estabelecendo um breve diálogo entre as proposições dos dois autores aqui mencionados, poderíamos dizer que a literatura, o texto literário, ao ser compreendido como obra de arte em sua multiplicidade polissêmica, como campo de jogo criador de múltiplos suplementos e múltiplas realidades, cria uma via de acesso simbólica ao inexprimível de alguns sentidos, ao indizível do discurso interior. Tal via de acesso possibilita a transposição de fronteiras e viabiliza, qualquer que seja a forma escolhida pelo leitor para encaminhar o jogo do texto, a busca de novas leituras sobre o vivido, a ampliação de experiências ou o prazer do próprio contato com suas formas de dizer ou com o encontro de novas formas de dizer.

Nessa perspectiva, a proposta metodológica com base na leitura, comentário e registro de impressões sobre contos e crônicas da literatura brasileira e universal endossa, com Yunes (2003), a ideia de que a leitura pode ser um importante instrumento de reaproximação com a vida, ressituando o leitor em relação a sua história, mas também à experiência que está sendo relatada no texto, numa dimensão ao mesmo tempo singular e plural.

Para isso, um grupo de 66 alunos - correspondentes a duas turmas de licenciatura da Universidade Federal Fluminense - foi convidado, no espaço das aulas de Psicologia da Educação, ao longo do primeiro semestre de 2008, a ler e a se expressar livremente sobre contos e crônicas da literatura brasileira através de depoimentos orais e escritos. Os contos e crônicas selecionados abordavam situações do contexto escolar. O registro desse conteúdo foi trabalhado a partir de unidades temáticas em torno de categorias escolhidas a priori, que remetem à experiência do ensinar e do aprender como: relação professor-aluno, processo ensino-aprendizagem, concepção de escola, entre outras. Tais eixos temáticos foram compreendidos e analisados dentro do contexto das narrativas suscitadas a partir da leitura dos textos.

Para esse trabalho, destacaram-se alguns relatos escritos e audiogravados, que, a partir da leitura do conto "Escrevo coisas e apago", de Vivina de Assis, e da crônica "Pensar", de Rubem Alves, revelam aspectos das concepções de um grupo de alunos das licenciaturas sobre a escola e suas funções. 
Textos literários e a formação do professor: novas possibilidades de narrar

\section{Uma experiência de leitura}

O conto "Escrevo coisas e apago", de Vivina de Assis, relata a experiência de uma menina no colégio de freiras, internato, destinado ao público feminino, cuja protagonista, no desenrolar da trama, relata seu total desinteresse por aquele contexto escolar, pelas pessoas que ali estão, como também por tudo que se relaciona ao processo de ensino e de aprendizagem. Na perspectiva da narradora, as experiências escolares não lhe ofereciam nada pelo qual pudesse se interessar, pela falta de sentido para sua vida; assim, assumia uma postura de indiferença, cumprindo apenas as normas e regras impostas, sem ousar questioná-las, pois questionar implicaria envolver-se, e isso era justamente o que não desejava. Dessa forma, usa algumas estratégias, como: fingir escutar, compreender e aceitar os conteúdos apresentados pelos professores, escrever e apagar diversas vezes as atividades - para os docentes pensarem que estivesse cumprindo suas obrigações -, mantendo uma falsa atitude de passividade para que não fosse incomodada por nenhum tipo de cobrança, já que sua opinião sobre tudo aquilo não seria mesmo considerada.

A seguir, algumas narrativas suscitadas pela leitura deste conto que narra experiências de escola, as quais nos remetem a algumas leituras de alunos de licenciatura a respeito de suas concepções sobre a escola:

Um ponto [que o texto suscita] é aprender a viver a partir da experiência dos outros. Eu penso na escola como reflexo da sociedade: a escola é onde você vai conhecer a instituição da família, a instituição do aprendizado, de todos os processos que as pessoas passam e quando você está numa escola, é você ter contato com a sociedade; tanto o aluno como você. Então, eu acho que você aprende a viver em sociedade também. O professor tem muito a aprender na sala de aula. (Aluno A)

Acho que o que a escola pode fazer é ajudar esse pensamento ir cada vez mais longe, a partir da identidade de cada um, a partir do ser de cada um. Alguns vão ter aptidão para determinadas questôes que outros não vão ter e vice-versa. O que a escola pode fazer é ser uma escola para ajudar o aluno a ter um pensamento abstrato, que é necessário pro conhecimento científico, um pensamento crítico sobre ele mesmo, sobre a sociedade. (Aluno B)

Agora eu acho que a escola não isola, porque a princípio alguém pode até se sentir isolado, mas para sobreviver na escola, a pessoa é obrigada a 
conviver. Mesmo que ela [a menina do conto] seja tímida, ela acaba tendo que conviver com outra pessoa e aquilo vai abrindo um pouco a mente dela. Mesmo que ela seja muito, sei lá, tenha alguma coisa estranha aos outros. Pega aí uma sétima série, sempre vai ter o narigudo, o cabeçudo, o barrigudo, vai ter sempre o diferente, o crente, o não sei o que, sempre vai haver isso. E essa pessoa vai se sentir sempre rejeitada de alguma forma, mas em algum momento ela vai ter que se coletivizar pra poder se manter. Até porque, é trabalho em grupo, é não sei o quê. A escola acaba meio que sem querer unindo as pessoas. (Aluno $\mathrm{C}$ )

Eu acho que a exclusão é própria da sociedade, a instituição escolar é uma parte da sociedade, então ela tem esse aspecto da exclusão sim. (Aluno D)

A escola não ensina a argumentar: ela te dá um leque de opções e a partir desse leque, você mesmo vai comparando, inconscientemente você compara uma opção com a outra e você vai formulando o seu próprio questionamento através das opçóes que ela te dá e ela dá porque, quando a gente entra na escola, a gente entra meio que, a gente não sabe muita coisa, ela te dá uma série de conteúdos, de conhecimentos que você não sabia antes. Então isso por si só, já te estimula a pensar e a questionar, comparar, entendeu? Acho que aí está a questão do raciocinar e criticar e não do pensar exatamente. (Aluno E)

A narrativa do autor se entrelaça com as experiências e concepções do leitor, nos revelando as diversas formas como as narrativas dos licenciandos jogam, no sentido discutido por Iser (2002), com a narrativa do conto.

Assim, enquanto os alunos A e B dialogam com as dificuldades da menina do conto de se interessar e se integrar na escola, a partir de reflexôes de como a escola deveria ser e o que deveria fazer para se tornar espaço de socialização e aprendizagem, como pode ser observado nos seguintes enunciados: "o professor tem muito a aprender na sala de aula" e "o que a escola pode fazer é ajudar esse pensamento ir cada vez mais longe", os alunos C, D e E parecem procurar justificativas para a escola ser como é: "a escola não isola", "a escola te dá um leque de opções", sugerindo que o problema de inadaptação da menina do conto à escola é um problema individual e que "mesmo que ela seja tímida ela acaba tendo que conviver com outra pessoa”.

De um modo geral, nos relatos, a relação da escola com a sociedade é tema recorrente, em que a escola é vista "como reflexo da sociedade", numa concepção onde o viés reprodutor parece predominar na 
Textos literários e a formação do professor: novas possibilidades de narrar

quase naturalização da exclusão. Sobre isso, o aluno E afirma: "a exclusão é própria da sociedade, a instituição escolar é parte da sociedade, então ela tem esse aspecto da exclusão", indicando que não haveria muito a fazer com os "inadaptados"; por outro lado, a ideia de socialização promovida pela escola parece ficar entendida também como uma contingência pelo fato da instituição induzir a atividades grupais, como no relato do aluno $\mathrm{D}$, que afirma que sempre vai existir uma pessoa "que vai se sentir rejeitada de alguma forma, mas que em algum momento ela vai ter que se coletivizar para poder se manter". Ou seja, embora a questão da socialização seja vista como uma função importante da escola, a mesma é compreendida como uma adaptação individual que se faz necessária a uma situação que é externa ao aluno, relativa à forma de organização de suas atividades e não como o resultado de um processo de reflexão sobre a questão da diferença. Esta concepção parece se confirmar quando o aluno coloca: "a escola acaba meio sem querer unindo as pessoas". Em vários trechos desses relatos, a instituição educacional também aparece como um lugar que deveria ter a importante função de desenvolver o pensamento do indivíduo. Sobre isso, o aluno C comenta: "o que a escola pode fazer é ser uma escola para ajudar o aluno a ter um pensamento abstrato que é necessário para o conhecimento científico, um pensamento crítico sobre ele mesmo, sobre a sociedade". Nesta linha, o aluno F diz: "a gente não sabe muita coisa, ela (a escola) te dá uma série de conteúdos, de conhecimentos que você não sabia antes. Então isso por si só, já te estimula a pensar e a questionar, comparar, entendeu? Acho que aí está a questão do raciocinar e criticar e não do pensar exatamente".

As observações dos alunos $\mathrm{C}$ e $\mathrm{F}$ mostram duas concepções que apontam para uma relação mecânica e automatizada na relação entre pensamento, conteúdo e desenvolvimento de funçóes como criticar, questionar e comparar. Para o aluno C, quando a escola desenvolve o pensamento abstrato, já dá condições ao aluno de desenvolver um pensamento crítico "sobre ele mesmo e a sociedade". O aluno F, por sua vez, parece entender que o simples contato com os conteúdos "já te estimula a pensar e a comparar...", sinalizando a visão tradicional de que cabe à escola e ao professor apresentar o conteúdo e, ao aluno, se desenvolver com ele, o que se daria em uma relação automática, revelando uma concepção dicotômica entre ensino, aprendizagem e desenvolvimento, na contramão de toda uma discussão desenvolvida sobre o tema, principalmente a realizada por Vigotski, em seu estudo sobre o desenvolvimento 
dos conceitos científicos na infância. Tais relatos se mostram reveladores de importantes questôes presentes nas concepções dos alunos das licenciaturas sobre a escola e suas funções.

Na crônica intitulada "Pensar", Rubem Alves faz uma reflexão sobre o pensar, relacionando-o ao ensinar e ao papel do professor, mostrando que existem várias formas de exercitar o pensamento, e alertando ainda para o perigo de sua cristalização pela escola. A seguir, algumas narrativas suscitadas pela crônica:

A minha experiência no tempo em que frequentava o colégio não foi muito motivadora. Faltava estímulo da parte dos professores, e então os alunos também não se interessavam. No colégio nunca me ensinaram a pensar, era tudo mecânico, eu reproduzia em exercícios o que aprendia na gramática. Eu acho que até hoje eu tenho dificuldade de expressar e escrever o que eu penso. (Aluno F)

$\mathrm{Na}$ minha opinião, o pensar na escola é meio desvalorizado. Os professores mecanizam a aprendizagem, tornando o pensar pouco útil. Existem disciplinas específicas para esse tipo de ato, isso faz muitas das vezes com que professores de outras disciplinas relaxem. Até mesmo nessas disciplinas específicas, como Filosofia e Sociologia, alguns professores não incentivam o pensar. (Aluno $\mathrm{G}$ )

$\mathrm{Na}$ minha experiência escolar tive algumas oportunidades diferentes de aprender a pensar. Por estudar a vida toda em colégio de freiras tive aulas de ensino religioso, onde era estimulada constantemente a pensar sobre diversos assuntos (...) acredito que a grande maioria dos professores não se preocupa em ensinar seus alunos a pensarem, ou a desenvolver suas ideias, por acreditarem que isso seja uma perda de tempo, tempo este que não poderia ser desperdiçado com algo diferente do conteúdo da disciplina que eles lecionam. A Filosofia seria a disciplina básica responsável pelo ensino do pensar, e ela seria quem tem a "obrigação" de ensinar as pessoas a pensarem. (Aluno $\mathrm{H}$ )

A experiência escolar com certeza ajuda a pensar, pois de alguma forma temos que chegar a uma solução. Por exemplo, ao ter uma conta para fazer, de alguma forma tem que sair um resultado. E com isso você acaba pensando. Se tiver um texto para ler, é importante o entendimento do mesmo e, sendo assim, você acaba pensando sobre o conteúdo do texto. (Aluno I)

Nas narrativas aqui apresentadas, parece haver uma compreensão de que a escola não "ensina a pensar" e que "os professores mecanizam a aprendizagem tornando o pensar pouco útil”. Nessa linha, mesmo as 
Textos literários e a formação do professor: novas possibilidades de narrar

disciplinas que supostamente deveriam ser responsáveis pelo pensar, como a Sociologia e a Filosofia, "não incentivam o pensar". O interessante é observar que o aluno $\mathrm{H}$, ao concordar com essa afirmação, coloca que o pensar deveria ser considerado quase um conteúdo a ser ensinado pela Filosofia, "que teria a obrigação de ensinar as pessoas a pensarem". $\mathrm{O}$ aluno I, ao seu turno, discordando dos relatos anteriores, afirma que a escola "com certeza ajuda a pensar", utilizando a justificativa de que o aluno na escola, "ao ter uma conta para fazer, de alguma forma tem que sair um resultado. E com isso você acaba pensando".

Essa narrativa curiosamente parece dialogar com alguns relatos suscitados pelo conto anterior, em especial com o do aluno D, ao dizer que "a escola meio sem querer acaba unindo as pessoas", e com o do aluno E, ao falar sobre o "leque de opções que a escola te dá", afirmando que "inconscientemente você compara uma opção com a outra e você vai formulando o seu próprio questionamento através das opções que ela [a escola] te dá".

Nessa direção, se observa que, para o aluno I, a escola também, meio sem querer, inconscientemente, através dos exercícios, leva o aluno a pensar. $\mathrm{O}$ que, levando em conta essas narrativas e o diálogo entre elas, poderia sugerir que, para esses alunos, tanto a função de socialização como a de desenvolvimento do pensamento são objetivos alcançados pela escola, como "efeitos" secundários produzidos de modo quase fortuito e inexorável, quaisquer que sejam as práticas pedagógicas realizadas e não como aspectos fundamentais do processo de conhecimento e de ensinoaprendizagem, que deveriam estar na base da reflexão sobre estas mesmas práticas.

\section{A literatura como experiência na formação do professor}

A título de conclusão, sempre provisória, torna-se importante destacar a importância da mediação da literatura nesta pesquisa, oferecendo o texto e o seu potencial simbólico para que os alunos das licenciaturas expressassem suas ideias e concepções sobre a escola. Ademais, como também mostra Yunes (2003), observa-se a possibilidade de ressituá-los em relação à experiência que está sendo contada, numa dupla oportunidade: a de se conectar com sua forma de pensar e a de repensar sobre a mesma. Embora os alunos das licenciaturas sejam universitários e possuam, 
portanto, vários anos de escolaridade, de um modo geral, não fazem de suas próprias experiências objeto de reflexão, nem encontram muitas vezes espaço para tal em sua trajetória de formação.

Nessa perspectiva, a experiência com a literatura aqui relatada revelou concepçóes que trazem em si, ao mesmo tempo, elementos de crítica, mas também aspectos de um pensamento tradicional e muitas vezes problemático em relação ao papel da escola e suas funções, enfatizando suas dimensôes reprodutivistas e conteudistas. Contudo, ao lado destas observações, também oferece uma rica oportunidade às diferentes disciplinas pedagógicas do curso de licenciatura de uma maior proximidade em relação às formas de pensar e sentir dos alunos, de transformá-las em um campo fértil para discussões, questionamentos e análises, pois, quando os alunos iniciam as disciplinas da licenciatura, já trazem concepçōes bastante solidificadas sobre o que é ensinar, sobre o que é aprender e sobre o papel da escola. Concepções certamente desenvolvidas ao longo das trajetórias escolares, embora, na maioria das vezes, como foi assinalado anteriormente, não sejam objeto de uma análise reflexiva. Dessa forma, conectar experiências individuais a experiências relatadas no texto literário, bem como aos diferentes conteúdos das disciplinas pedagógicas presentes na formação inicial, pode ser apenas uma das muitas possibilidades que a literatura pode oferecer. Tais conexões, ao proporcionarem uma experiência não apenas na dimensão teórico-conceitual, mas também na dimensão subjetivo-significativa, trazem outras perspectivas de leitura para a relação entre subjetividade, experiência e conteúdo.

\section{Referências}

ALVES, R. Pensar. In: ALVES, R. Ao professor com meu carinho. Campinas: Verus, 2004.

ASSIS, V. Escrevo coisas e apago. In: FÉLIX, H. (Ed.). Professor e aluno. São Paulo: Atual, 1994. (Série/coleção Vínculos).

BEZERRA, P. Um crítico muito original. In: VIGOTSKI, L.S. A tragédia de Hamlet, príncipe da Dinamarca. São Paulo: Martins Fontes, 1999.

CASTORIADIS, C. A instituição imaginária da sociedade. Rio de Janeiro: Paz \& Terra, 1991. 
Textos literários e a formação do professor: novas possibilidades de narrar

ISER, W. O jogo do texto. In: COSTA, L. (Coord.; trad.). A literatura e o leitor: textos da estética da recepção. Rio de Janeiro: Paz \& Terra, 1979.

VIGOTSKI, L.S. A tragédia de Hamlet, príncipe da Dinamarca. São Paulo: Martins Fontes, 1999.

VIGOTSKI, L.S. Pensamento e linguagem. São Paulo: Martins Fontes, 2005.

YUNES, E. Leitura como experiência. In: YUNES, E.; OSWALD, M.L. (Org.). A experiência da leitura. São Paulo: Loyola, 2003.

Recebido em $1^{\circ}$ de setembro de 2010. Aprovado em 17 de março de 2011. 